Pathophysiology of Haemostasis and Thrombosis
Pathophysiol Haemost Thromb 2003;33:144-156

DOI: $10.1159 / 000077823$
Received: April 23, 2003

Accepted after revision: January 7, 2004

\title{
Effects of Surgical Trauma and Cardiopulmonary Bypass on Active Thrombin Concentrations and the Rate of Thrombin Inhibition in vivo
}

\author{
Tomas Velan Wayne L. Chandler \\ Department of Laboratory Medicine, University of Washington, Seattle, Wash., USA
}

\section{Key Words}

Acquired coagulation disorders · Thrombin .

Antithrombin · Inhibition kinetics · Cardiopulmonary

bypass $\cdot$ Surgery

\begin{abstract}
The in vivo concentration of active thrombin and the second-order rate constant for the inhibition of thrombin by antithrombin $\left(\mathrm{k}_{\mathrm{inh}}\right)$ were estimated in patients undergoing cardiopulmonary bypass (CPB) based on measured levels of hemostatic markers in combination with a computer model of the patient's hemostatic and vascular systems. At baseline $\mathrm{k}_{\mathrm{inh}}=0.6 \pm 0.1 \mu \mathrm{M}^{-1} \mathrm{~s}^{-1}$ leaving $270 \pm$ $101 \mathrm{f} M$ of active thrombin in the circulation. These factors were unchanged after sternotomy. Soon after heparin administration and the start of $C P B, \mathrm{k}_{\text {inh }}$ increased 25fold resulting in decreased active thrombin. After CPB and heparin neutralization, $\mathrm{k}_{\text {inh }}$ decreased to 8-fold above baseline allowing active thrombin levels to rise. Both factors had returned to normal $2 \mathrm{~h}$ after surgery. We conclude that $\mathrm{CPB}$ with heparinization results in a rapid increase in thrombin inhibition leading to decreased active thrombin levels in vivo.
\end{abstract}

Copyright $@ 2003$ S. Karger AG, Basel

\section{Introduction}

Thrombin, formed by the cleavage of the prothrombin by prothrombinase complex, is the final enzyme product of the blood coagulation cascade. The regulation of thrombin production and inhibition is vital to the maintenance of the hemostatic balance. Once formed, active thrombin converts fibrinogen into fibrin releasing fibrinopeptides A (FPA) and B (FPB), activates platelets and participates in a host of other coagulation-related processes. Active thrombin has multiple targets including protein $\mathrm{C}$, factors V, VIII, XI, XIII and thrombin-activatable fibrinolysis inhibitor [1]. Fibrinogen is one of the most important targets of thrombin due to its high concentration $(7 \mu M)$ and rapid rate of reaction $\left(\mathrm{k}_{\mathrm{cat}} / \mathrm{K}_{\mathrm{m}}=\right.$ $\left.11.7 \mu M^{-1} \mathrm{~s}^{-1}\right)[2]$.

In vitro four thrombin inhibitors have been described in pure systems or plasma: antithrombin, heparin cofactor II, $\alpha_{2}$-macroglobulin, and $\alpha_{1}$-protease inhibitor [3]. Among these inhibitors, antithrombin is the most important due to its high concentration $(2.4 \mu M)$ and fast reaction rate with thrombin in the presence of heparin or its endothelial equivalent heparan sulfate proteoglycans [4]. The reported in vitro second-order rate constant for the inhibition of thrombin by antithrombin $\left(\mathrm{k}_{\mathrm{inh}}\right)$ in the presence of heparin has ranged from 18 to $670 \mu M^{-1} \mathrm{~s}^{-1}$ with heparan acceleration being very similar [5-7]. In vitro

Wayne L. Chandler, MD

Department of Laboratory Medicine

Box 357110, University of Washington

Seattle, WA $98195-7110$ (USA)

Tel. +1 206598 6131, Fax +1 206598 6189, E-Mail wlc@u.washington.edu
Fax +4161306 1234

E-Mail karger@karger.ch

www.karger.com

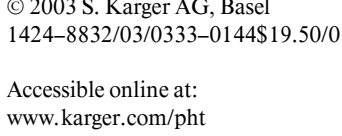


studies using adult plasma indicate that when heparin is present, 94-97\% of thrombin generated in plasma is inhibited by antithrombin, with $1-3 \%$ inhibited by $\alpha_{2}-$ macroglobulin and $1-4 \%$ by heparin cofactor II $[8,9]$. In the absence of heparin, $\mathrm{k}_{\text {inh }}$ ranges from 0.006 to $0.007 \mu M^{-1} \mathrm{~s}^{-1}[5,10,11]$.

The rate of thrombin inhibition in vivo is unknown. It is likely that in vivo the rate of thrombin inhibition is not constant, but varies depending on a variety of factors including the concentration of antithrombin and other inhibitors, the concentration of heparin or heparan, and whether active thrombin is free in the plasma or bound to fibrin, platelets or other receptors such as thrombomodulin. Binding to fibrin slows but does not prevent thrombin from being inhibited both in the presence and absence of heparin [12].

The purpose of this study was to estimate the rate of thrombin generation, the apparent second-order rate constant $\mathrm{k}_{\mathrm{inh}}$ and the concentration of active thrombin occurring in vivo during open-heart surgery utilizing cardiopulmonary bypass (CPB). Open-heart surgery was studied as the experimental model as it results in a variety of conditions that could affect thrombin regulation including hemostatic stress (surgical trauma), increased thrombin generation due to exposure of blood to the artificial surface of the bypass circuit, heparinization and heparin neutralization [13]. The in vivo rate of thrombin generation was based on the concentrations of the prothrombin activation peptide F1.2 and the thrombin-antithrombin complex (TAT). Estimates of active thrombin concentrations and $\mathrm{k}_{\mathrm{inh}}$ in vivo were based on the thrombin-generation rate and the concentrations of FPA, fibrinogen and antithrombin and their kinetic interactions.

\section{Methods}

\section{Human Subjects}

Studies on human subjects were carried out according to the principles of the Declaration of Helsinki. Informed consent was obtained from all participants and the study was approved by the University of Washington Human Subjects Review Committee. A total of 9 men were studied ranging in age from 50 to 74 (mean $59 \pm 7$ ) years. All subjects underwent coronary artery bypass graft surgery utilizing standard CPB. All patients received routine anesthetic and surgical care including 'balanced' anesthesia (fentanyl, etomidate, isoflurane, pancuronium). Porcine heparin was administered as a loading dose of $250 \mathrm{IU} / \mathrm{kg}$, and supplemented as needed to maintain a kaolin-activated clotting time of $>450 \mathrm{~s}$ during bypass. CPB utilized a membrane oxygenator, arterial filter and centripetal pump head. Heparinization was reversed with protamine sulfate following completion of CPB. Cardiac output was measured using thermodilution catheters.

\section{Blood Sampling}

Blood was collected from an arterial line at 10 time points (average time from the start of the procedure in $\min \pm \mathrm{SD}$ in parentheses): (1) baseline - after induction of anesthesia ( $0 \pm 0$, arbitrary); (2) after sternotomy (34 \pm 15$)$; (3) after heparin administration (73 \pm 16$)$; (4) after $5 \mathrm{~min}$ of CPB (117 \pm 42$)$; (5) $15 \mathrm{~min}$ of CPB (127 \pm 44$)$; (6) $30 \mathrm{~min}$ of CPB $(145 \pm 42)$; (7) prior to reperfusion of the heart (188 \pm 44); (8) after reperfusion (204 \pm 46$)$; (9) after protamine administration $(245 \pm 57)$, and (10) $2 \mathrm{~h}$ after surgery $(432 \pm 70)$. At each time point $4.5 \mathrm{ml}$ of arterial blood was added to $0.5 \mathrm{ml}$ of $0.105 M$ citrate for assays of antithrombin activity, and fibrinogen, while $5 \mathrm{ml}$ of arterial blood was anticoagulated with $11 \mathrm{mM}$ citrate and $25 \mathrm{~m} M$ PPACK for assays of F1.2, TAT, and FPA. All samples were immediately centrifuged at $1,800 \mathrm{~g}$ for $30 \mathrm{~min}$ at $4{ }^{\circ} \mathrm{C}$, aliquoted and frozen at $-80^{\circ} \mathrm{C}$ until analyzed.

\section{Assay Methods}

F1.2 and TAT were measured using enzyme immunoassays (Dade-Behring) $[14,15]$. FPA was measured using a modified competitive immunoassay according to Amiral et al. [16]. Antithrombin was measured using a chromogenic method (Stago) [17]. Fibrinogen was measured using a kinetic clottable method (Stago) [18]. Measured levels for each assay for all subjects have been reported previously [19].

\section{Thrombin Regulation Model}

We estimated the in vivo thrombin-generation rate, $\mathrm{k}_{\mathrm{inh}}$ and active thrombin concentration for each subject in the study. Two types of models were used: a steady-state model that evaluated these factors only at baseline under approximately steady-state conditions, and dynamic vascular models that were able to estimate these factors in each subject during each time interval sampled, before, during and after CPB. The steady-state model assumes all concentrations are constant in the subject. The dynamic vascular models used computer simulations of the human vascular system combined with a kinetic model of thrombin generation, activity and inhibition to analyze aspects of hemostatic regulation, while the hemostatic system is undergoing changes due to surgery and CPB. This study represents the second generation of a hemostatic and vascular model published previously [19]. In the prior study we estimated the rates of thrombin generation based on F1.2 and TAT levels and the rate of fibrin formation based on FPA levels. The vascular model was used to account for changes in marker clearance, hemodilution by the bypass circuit priming fluid, blood loss and transfusion. There was no linkage between any of the hemostatic factors in the model, it was used simply to estimate the rate of these processes in vivo. In this study the model has been extended to include a linked kinetic model incorporating thrombin generation, thrombin inhibition by antithrombin and thrombin activity releasing FPA from fibrinogen.

Figure 1 shows the kinetic model used in this study. Each time a thrombin molecule is formed, the kinetic model assumes that an F1.2 is formed along with it. Active thrombin can either react with fibrinogen or be inhibited by antithrombin forming TAT. To simplify the model, we assumed that fibrinogen was the only substrate for thrombin and that antithrombin was the only inhibitor for thrombin. The predicted in vivo thrombin generation rate was determined by adjusting the thrombin generation rate in the model to produce the best fit between measured and simulated levels of F1.2 and TAT.

There are two ways of expressing the thrombin generation rate. The first is the local rate of thrombin generation per liter of plasma 


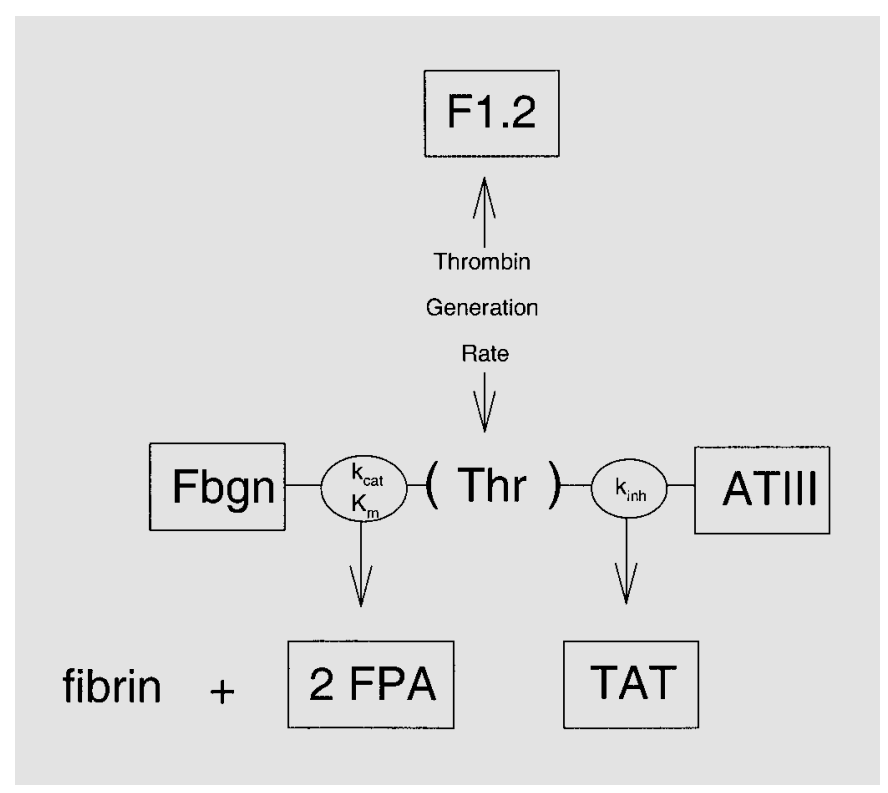

Fig. 1. Overall schema of thrombin regulation. Thrombin generation produces prothrombin activation peptide $\mathrm{F} 1.2$ and active thrombin (Thr) which can either react with fibrinogen (Fbgn) forming fibrin and 2 fibrinopeptides A (FPA), or it can be inhibited by antithrombin (ATIII) forming thrombin-antithrombin (TAT) complex. $\mathrm{k}_{\text {cat }}$ and $\mathrm{K}_{\mathrm{m}}$ are constants for the reaction between fibrinogen and thrombin (table 1). $\mathrm{k}_{\text {inh }}$ is the apparent in vivo second-order reaction rate between thrombin and antithrombin forming TAT.

(moles liter ${ }^{-1}$ second $^{-1}$ ). This type of expression is used when the thrombin generation is linked to other processes through a kinetic model as in this study. Thrombin being added to the plasma is reacting with antithrombin and fibrinogen, so the local rate of change per volume is needed. The second way of expressing thrombin generation rates is the total amount of thrombin produced throughout the vasculature (moles second ${ }^{-1}$ ). Total thrombin generation is equal to local thrombin generation times plasma volume [20]. Total thrombin generation is used when the plasma volume is changing. For example, when CPB starts, the patient's plasma volume is expanded and diluted by the priming fluid in the CPB circuit. F1.2 and TAT levels rise after $\mathrm{CPB}$, even though the plasma is diluted, indicated a rapid rise in local and total thrombin generation. In a prior study, we reported total thrombin generation rates to give an overall impression of the total rise in thrombin generation during CPB [19]. In this study we report thrombin generation rates as local rates (moles liter ${ }^{-1}$ second $^{-1}$ ) because the thrombin generated is feeding into a kinetic model.

In vivo there are different forms of active thrombin including thrombin free in plasma and thrombin bound to a variety of proteins, receptors and cell surfaces including fibrinogen, fibrin, platelets and endothelium. Thrombin is inhibited by antithrombin and other inhibitors at different rates depending on the form of active thrombin (bound or free) and whether antithrombin is free or bound to and accelerated by heparin or heparan. The apparent in vivo $\mathrm{k}_{\text {inh }}$ determined in this study represents the average or overall rate constant. It suggests what the predominant rate is. Likewise, the active thrombin concentration in this study is an average of all the forms of active thrombin that can cleave fibrinogen to fibrin, and assumes that all forms of active thrombin cleave fibrinogen at the same rate, even though in vivo fibrinogen activation may be occurring at several different rates based on the form of active thrombin.

The effect of $\mathrm{k}_{\mathrm{inh}}$ was studied in two ways. In models $\mathrm{A}$ and $\mathrm{B}, \mathrm{k}_{\mathrm{inh}}$ was held constant at the approximate minimum rate determined in vitro for free antithrombin and the approximate maximum value determined in vitro when antithrombin is maximally accelerated by heparin [11]. Fibrinogen and antithrombin concentrations were initially set to baseline levels, with thrombin generation determined as described above. The simulation was then run using the fixed $\mathrm{k}_{\text {inh }}$ with the model predicting what the effect would be on active thrombin, fibrinogen and FPA levels based on changes in the thrombin generation rate. Higher $\mathrm{k}_{\text {inh }}$ leads to more rapid thrombin inhibition and lower predicted FPA levels, lower $\mathrm{k}_{\text {inh }}$ leads to slower thrombin inhibition and higher predicted FPA levels. In model $\mathrm{C}, \mathrm{k}_{\text {inh }}$ was adjusted to produce the best fit between measured and simulated levels of FPA, resulting in an estimate of the apparent average in vivo $\mathrm{k}_{\text {inh }}$ for each time point in the study.

The vascular model accounts for the effects marker clearance, hemodilution, blood loss and transfusion have on marker levels as previously described [19]. Briefly, the total blood volume, blood flow, plasma protein concentrations and hematocrit in the model are set to the measured baseline levels in the subject being studied. Likewise, the bypass circuit priming fluid volume and bypass circuit output during CPB are set to the actual values. Urine output, blood loss, and transfusion history were extracted from anesthesia flow charts, cell saver documentation and surgical operative notes. By matching all the parameters in the circulatory model to the measured values in the patient, the circulatory model can be used to account for changes these processes have on the concentration of proteins in the blood. In the prior study we evaluated the vascular model's accuracy in simulating hemodilution and the effect of blood volume, simulation of blood loss and transfusion and simulation of marker clearance.

In this study, two types of dynamic vascular models were evaluated, a single segment model that assumes the vascular system is a single large well-mixed pool and a circulatory model which distributes blood flow into coronary, cerebral, upper extremity, splanchnic, renal, lower extremity and remaining ('other') circulations (fig. 2). Single-segment vascular models work well when changes in the concentration of factors occur slowly over hours to days and there are no regional differences in the concentration of the factor in the vascular

Fig. 2. Dynamic vascular models. The figures on the left show the two dynamic vascular models studied, a single segment model assuming that all the blood is a single well-mixed pool, and a circulatory model which shows the relative arterial, microvascular (shaded) and venous blood volumes for different regions of the model. The circulatory model has been described in detail previously [19]. Total blood volume and cardiopulmonary bypass circuit volume in the model are adjusted to match the individual subject being simulated for both dynamic models. Graphs on the right show the simulated $(-)$ versus measured $(0)$ levels of a dye in the pulmonary artery and radial artery after bolus infusion over $5 \mathrm{~s}$ [25]. 


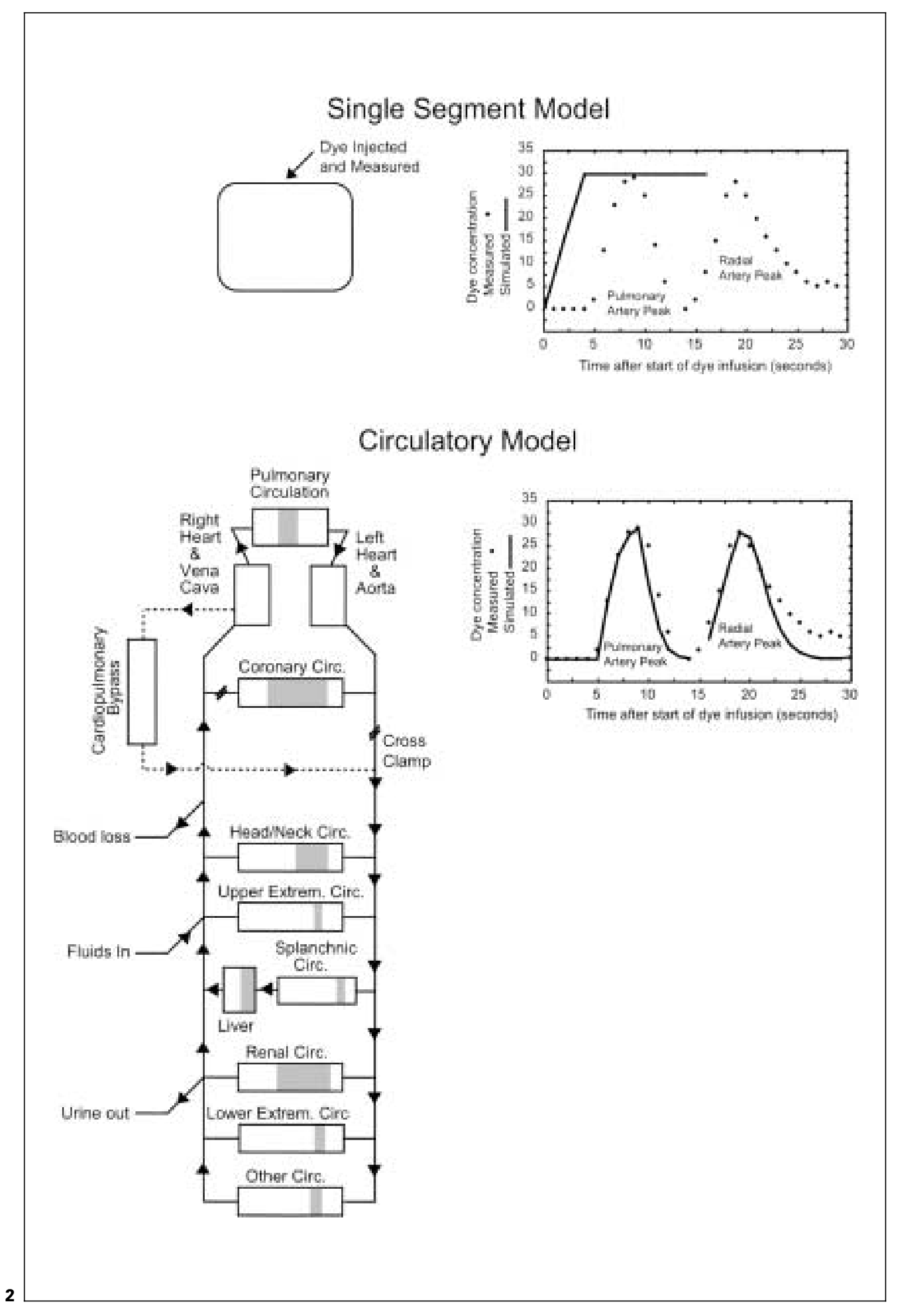


Table 1. Kinetic equations used in the model

$$
\begin{array}{ll}
\text { Thrombin }+ \text { fibrinogen } \stackrel{\mathrm{k}_{1}}{\longrightarrow} \text { thrombin/fibrinogen } & \mathrm{K}_{\mathrm{m}}=7.2 \times 10^{-6} M[2] \\
\text { Thrombin/fibrinogen } \stackrel{\mathrm{k}_{-1}}{\longrightarrow} \text { thrombin + fibrinogen } & \mathrm{k}_{\mathrm{cat}}=84 \mathrm{~s}^{-1}[2] \\
& \mathrm{k}_{\mathrm{D}}=1.8 \times 10^{-6}[34] \\
& \mathrm{k}_{1}=1.56 \times 10^{7} M^{-1} \mathrm{~s}^{-1} \\
\text { Thrombin/fibrinogen } \stackrel{\mathrm{k}_{2}}{\longrightarrow} \text { thrombin + fibrin + FPA } & \mathrm{k}_{-1}=28.0 \mathrm{~s}^{-1} \\
& \mathrm{k}_{2}=84 \mathrm{~s}^{-1} \\
& \mathrm{k}_{\text {inh }}=\text { variable }
\end{array}
$$

system, thus allowing the factor level to be well mixed and constant through the vasculature. Circulatory models work better when concentration changes occur rapidly, such as bolus infusion, or regional differences exist as seen in the fibrinolytic system where venous levels of tissue plasminogen activator are higher than arterial levels due to secretion from endothelium in the capillary beds [21, 22]. An extensive evaluation of the circulatory model has been presented in a prior study and an accompanying on-line appendix [19]. Complete details of the computer program including a copy of the source code, an explanation of how the model works and the data set used in the model are available at:

http://depts.washington.edu/labweb/dept/staff/bios/hemostas/

\section{Statistical Evaluation}

Group distributions are presented as the mean \pm standard error of the mean. Comparisons within group used repeated measures analysis of variance (ANOVA) and the Fisher Least Significant Difference test. Statistica ${ }^{\mathrm{TM}}$ software (Stat-Soft ${ }^{\mathrm{TM}}$, Tulsa, Okla., USA) was used for all statistical calculations. Thrombin inhibition rate values were $\log$ transformed before statistical evaluation.

\section{Results}

\section{Steady-State Model}

At steady state, the FPA generation rate by active thrombin will be equal to the FPA clearance rate:

$$
\frac{\mathrm{k}_{\mathrm{cat}} \mathrm{C}_{\mathrm{Thr}} \mathrm{C}_{\mathrm{Fib}}}{\left(\mathrm{K}_{\mathrm{m}}+\mathrm{C}_{\mathrm{Fib}}\right)}=\mathrm{k}_{\mathrm{FPA}} \mathrm{C}_{\mathrm{FPA}}
$$

where $\mathrm{k}_{\mathrm{FPA}}=\ln 2 / \mathrm{t}_{1 / 2}$ (for FPA $\mathrm{t}_{1 / 2}=4 \mathrm{~min}$ ) [23], $\mathrm{C}_{\mathrm{FPA}}$, $\mathrm{C}_{\mathrm{Fib}}, \mathrm{C}_{\mathrm{Thr}}$ are the respective concentrations for FPA, fibrinogen and total active thrombin (i.e. free and bound to fibrinogen) and $\mathrm{k}_{\mathrm{cat}}$ and $\mathrm{K}_{\mathrm{m}}$ are constants for FPA formation (table 1) [2]. The 9 subjects in this study had an average fibrinogen concentration of $11 \pm 1 \mu M$ and FPA concentration of $4.5 \pm 1.8 \mathrm{nM}$, resulting in an estimated average in vivo active thrombin concentration at baseline of $250 \pm 94 \mathrm{fM}$.

Fibrinogen reduces the rate of thrombin inhibition by antithrombin by competing for the active site of thrombin
[24]. We assumed that antithrombin was the only inhibitor of thrombin and that thrombin bound to fibrinogen does not react with antithrombin:

$$
\mathrm{C}_{\mathrm{FreeThr}}=\frac{\mathrm{C}_{\mathrm{Thr}} \mathrm{K}_{\mathrm{m}}}{\mathrm{K}_{\mathrm{m}}+\mathrm{C}_{\mathrm{Fib}}}
$$

The apparent free active thrombin concentration $\left(\mathrm{C}_{\mathrm{FreeThr}}\right)$ is a function of the thrombin generation rate (TGR) and the thrombin inhibition rate:

$$
\frac{\mathrm{dC}_{\text {FreeThr }}}{\mathrm{dt}}=0=\mathrm{TGR}-\mathrm{k}_{\text {inh }} \mathrm{C}_{\text {FreeThr }} \mathrm{C}_{\text {ATIII }}
$$

where $\mathrm{C}_{\mathrm{ATIII}}$ is the antithrombin concentration, TGR = $\mathrm{k}_{\mathrm{F} 1.2} \mathrm{C}_{\mathrm{F} 1.2}$ and $\mathrm{k}_{\mathrm{F} 1.2}=\ln 2 / \mathrm{t}^{1 / 2}\left(\right.$ for $\left.\mathrm{F} 1.2 \mathrm{t}^{1 / 2}=90 \mathrm{~min}\right)$ [20]. Solving for $\mathrm{k}_{\text {inh }}$ :

$$
\mathrm{k}_{\text {inh }}=\frac{\mathrm{k}_{\mathrm{F} 1.2} \mathrm{C}_{\mathrm{F} 1.2} \mathrm{k}_{\mathrm{cat}} \mathrm{C}_{\mathrm{Fib}}}{\mathrm{k}_{\mathrm{FPA}} \mathrm{C}_{\mathrm{FPA}} \mathrm{C}_{\mathrm{ATIII}} \mathrm{K}_{\mathrm{m}}}
$$

$\mathrm{k}_{\text {inh }}$ is in effect an estimate of the average rate constant for all the different forms of thrombin (free versus bound) and antithrombin (free versus accelerated by heparin or heparan). For the 9 subjects in the study, the baseline antithrombin concentration was $2.3 \pm 0.1 \mu M$, resulting in an estimated steady-state in vivo $\mathrm{k}_{\mathrm{inh}}=0.7 \pm 0.2 \mu M^{-1} \mathrm{~s}^{-1}$.

\section{Dynamic Cardiopulmonary Bypass Models}

Two different dynamic vascular models were evaluated, a single-segment model and a multi-segment circulatory model (fig. 2). Single-segment models assume that the blood is a single large well-mixed pool and that all changes occur simultaneously throughout the blood volume. Circulatory models separate the blood volume into separate circulatory loops representing different parts of the vascular system including cerebral, coronary, renal, splanchnic, etc. There are several potential reasons why a single-segment model might not be a good assumption for modeling thrombin regulation during CPB. First, the rapid clearance of FPA (half-life 4 min) leads to a large arterial venous difference in FPA levels across the liver. Rapid 


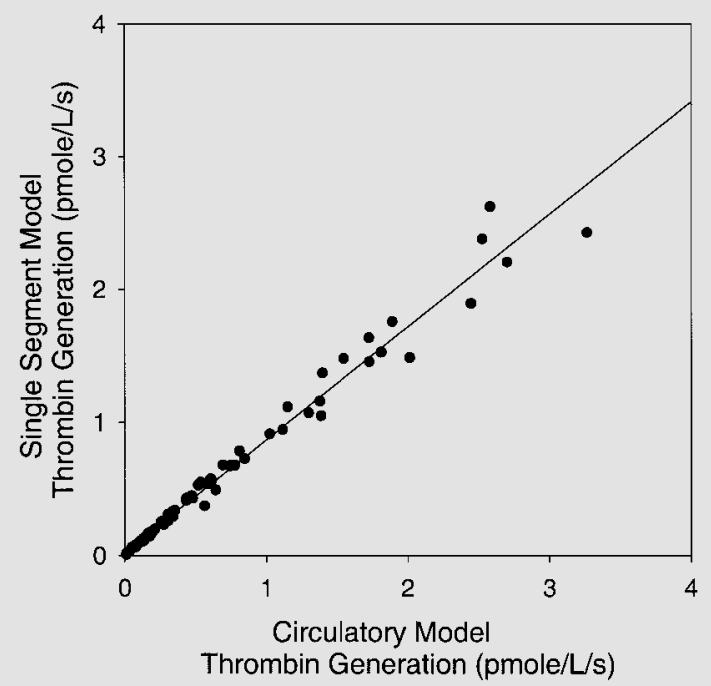

Fig. 3. Comparison of thrombin generation rates estimated using the single segment versus circulatory models. - Thrombin generation rates for all 10 time points in all 9 subjects $(\mathrm{n}=90)$; $-=$ Linear regression fit.

changes in thrombin and FPA generation, and short time intervals (minutes) between sample points could lead to situations where the concentration of factors in the vascular system are not at equilibrium (constant throughout).

To test whether the two dynamic vascular models produce the same results in the CPB study, we compared the estimated thrombin-generation rates for the single segment and circulatory models for all time points in all 9 subjects (fig. 3). While there was a good correlation between the thrombin-generation rates in the two dynamic models $\left(r^{2}=0.980\right)$, the rate in the single-segment model was on average $15 \%$ lower than in the circulatory model and up to $50 \%$ different at some time points. Figure 4 shows that the difference between the single-segment and circulatory models was greatest when the time interval between samples was short (minutes), such that the circulatory model had not reached equilibrium while the single-segment model assumes that equilibrium occurs instantly.

To test which model was best at simulating rapid changes in concentration, we compared the measured versus simulated levels of a dye in the pulmonary artery and radial artery (study sample point) after the bolus infusion of dye over $5 \mathrm{~s}$ [25]. Figure 2 shows that, in the singlesegment model, the dye concentration rises linearly dur-

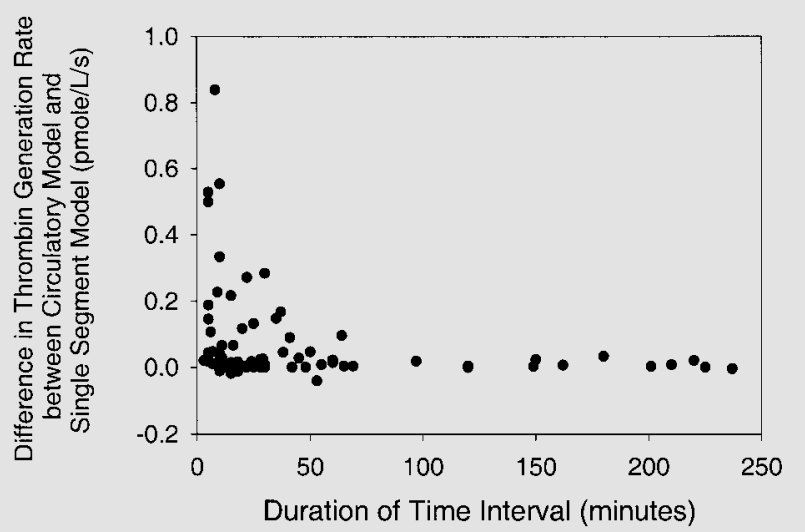

Fig. 4. Comparison of the time interval duration between sample points and the difference in thrombin generation rate between the single segment versus the circulatory model. ing infusion and then remains constant throughout the vascular system. In reality, the dye concentration peaks and then falls in various areas of the vascular system over the first minute or so as the dye bolus circulates around the body. The circulatory model shows a much closer fit to the measured dye concentrations in the pulmonary artery and radial artery. The circulatory model was better at simulating the effect of rapid change and short sampling times on the concentration of factors in the blood. It was used for all future simulations.

\section{Thrombin Inhibition Models}

Three different models of thrombin regulation using the circulatory model were evaluated. In model $\mathrm{A}, \mathrm{k}_{\mathrm{inh}}$ was held constant at $0.007 \mu M^{-1} \mathrm{~s}^{-1}$, the approximate in vitro rate of antithrombin inhibition of free thrombin in the absence of heparin or heparan [11]. This represents an approximate lower limit from in vitro studies. Figure 5 shows an example of the output from model A for 1 subject. Simulated values for F1.2, antithrombin and TAT fit the measured data well. Thrombin generation increased immediately after going on CPB and again after reperfusion of the ischemic heart. The model predicted that at this slow rate of thrombin inhibition, active thrombin concentrations would be high and most of the fibrinogen 
Model A: slow thrombin inhibition $\mathrm{k}_{\mathrm{inh}}=7.0 \times 10^{3} \mathrm{M}^{-1} \mathrm{~s}^{-1}$

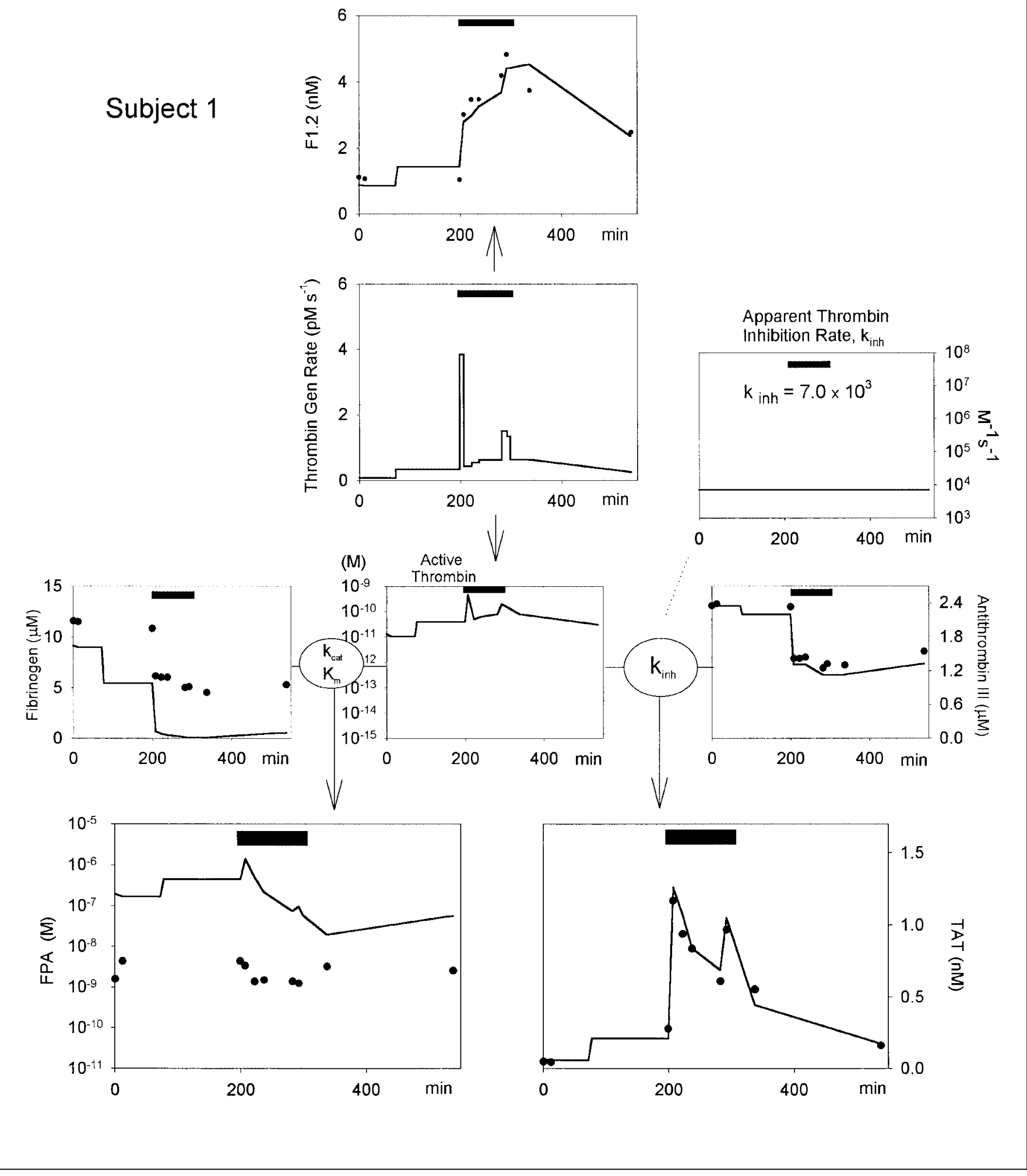


would be converted into fibrin and FPA. Measured fibrinogen levels were higher than predicted, while measured FPA levels were lower than predicted indicating that in vivo, the average $\mathrm{k}_{\mathrm{inh}}$ is likely faster than $0.007 \mu M^{-1} \mathrm{~s}^{-1}$.

In model $\mathrm{B}, \mathrm{k}_{\text {inh }}$ was held constant at $28 \mu M^{-1} \mathrm{~s}^{-1}$, the approximate in vitro rate for antithrombin inhibition of free thrombin in the presence of saturating heparin or heparan [11]. This represents an approximate upper limit from in vitro studies. Figure 6 shows an example of the output from model B for the same subject shown in figure 5. Simulated values for F1.2, antithrombin, fibrinogen and TAT fit the measured data well. The pattern of thrombin generation was similar to that seen for model A above, but the peak thrombin-generation rates were lower in model B due to the faster formation of TAT which was used with F1.2 to predict thrombin generation. Even though the pattern of thrombin generation was similar for models A and B, the more than a 1,000-fold increase in $\mathrm{k}_{\text {inh }}$ used in model B lead to a 1,000-fold decrease in the predicted active thrombin concentration. Lower active thrombin levels lead to less fibrinogen consumption and FPA generation. The agreement between measured and simulated fibrinogen levels was excellent, most of the change in fibrinogen was due to hemodilution, blood loss and transfusion, not thrombin activity. The predicted FPA levels in the model were generally lower than the measured levels, particularly at baseline and postoperatively. This indicates that the apparent in vivo $\mathrm{k}_{\text {inh }}$ during baseline and postoperatively is likely lower than $28 \mu M^{-1} \mathrm{~s}^{-1}$.

In model $\mathrm{C}$, the apparent second-order rate constant of thrombin inhibition in vivo was adjusted to produce the best fit between measured and simulated levels of FPA. Figure 7 shows an example for the same subject shown in figures 5 and 6 . Figure 8 shows the average results for all 9 subjects. At baseline the apparent $\mathrm{k}_{\text {inh }}$ was on average 0.6 $\pm 0.1 \mu M^{-1} \mathrm{~s}^{-1}$ resulting in an average active thrombin

Fig. 5. Output from thrombin regulation model A for subject 1 . The second-order rate constant for thrombin inhibition by antithrombin $\left(\mathrm{k}_{\text {inh }}\right)$ was held constant at the approximate in vitro rate in the absence of heparin, 0.007.0 $\mu M^{-1} \mathrm{~s}^{-1}$ [11]. Each graph shows the predicted result (-) from the computer model versus the measured level of each factor (-) for comparison. Note that a log scale is used for the $y$-axis of the thrombin inhibition, active thrombin concentration and fibrinopeptide A (FPA) concentration. The black bar at the top of each graph shows the period of cardiopulmonary bypass. concentration of $270 \pm 101 \mathrm{fM}$. The active thrombin concentration and $\mathrm{k}_{\mathrm{inh}}$ did not change significantly after sternotomy or $5 \mathrm{~min}$ after administration of heparin. Within 5 min of starting $\mathrm{CPB}$, the thrombin generation rate increased on average 14-fold $(\mathrm{p}=0.0001)$, while $\mathrm{k}_{\text {inh }}$ increased 25 -fold $(\mathrm{p}=0.000000)$. This resulted in a $77 \%$ $(p=0.01)$ decrease in the predicted active thrombin concentration. During the remainder of $\mathrm{CPB}$, the average thrombin generation rate was modestly increased with an average $\mathrm{k}_{\text {inh }}$ of $11.5 \pm 5.1 \mu M^{-1} \mathrm{~s}^{-1}$ and active thrombin concentration of $82 \pm 15 \mathrm{fM}(\mathrm{p}<0.01)$. After reperfusion of the ischemic heart, the thrombin-generation rate increased again as did $\mathrm{k}_{\mathrm{inh}}=16.6 \pm 5.4 \mu M^{-1} \mathrm{~s}^{-1}(\mathrm{p}=$ 0.000001 ), while the active thrombin concentration remained low. After heparin neutralization by protamine the thrombin-generation rate remained elevated while $\mathrm{k}_{\text {inh }}$ decreased 3-fold $(\mathrm{p}=0.002)$, resulting in a 4-fold $(\mathrm{p}=$ $0.00004)$ increase in the active thrombin concentration. During the postoperative period, $\mathrm{k}_{\mathrm{inh}}$ and the active thrombin concentration returned to baseline levels. There was good agreement between measured and simulated antithrombin concentrations in all 3 models since the total consumption of antithrombin by thrombin was always small. The majority of the changes in antithrombin concentration were due to hemodilution, blood loss and transfusion.

(For fig. 6 and 7 see next pages.)

Fig. 6. Output from thrombin regulation model B for subject 1 . The second-order rate constant for thrombin inhibition by antithrombin $\left(\mathrm{k}_{\text {inh }}\right)$ was held constant at the approximate in vitro rate in presence of saturating heparin, $28 \mu M^{-1} \mathrm{~s}^{-1}$ [11]. Each graph shows the predicted result (-) from the computer model versus the measured level of each factor ( ) for comparison. Note that a log scale is used for the $y$-axis of the thrombin inhibition, active thrombin concentration and fibrinopeptide A (FPA) concentration. The black bar at the top of each graph shows the period of cardiopulmonary bypass.

Fig. 7. Output from thrombin regulation model $\mathrm{C}$ for subject 1 . The second-order rate constant for thrombin inhibition by antithrombin $\left(\mathrm{k}_{\mathrm{inh}}\right)$ was adjusted to produce the best fit between measured and simulated levels of fibrinopeptide A (FPA). Each graph shows the predicted result (-) from the computer model versus the measured level of each factor (-) for comparison. Note that a log scale is used for the y-axis of the thrombin inhibition, active thrombin concentration and FPA concentration. The black bar at the top of each graph shows the period of cardiopulmonary bypass. 
Model B: fast thrombin inhibition $\mathrm{k}_{\mathrm{mh}}=2.8 \times 10^{7} \mathrm{M}^{-1} \mathrm{~s}^{-1}$

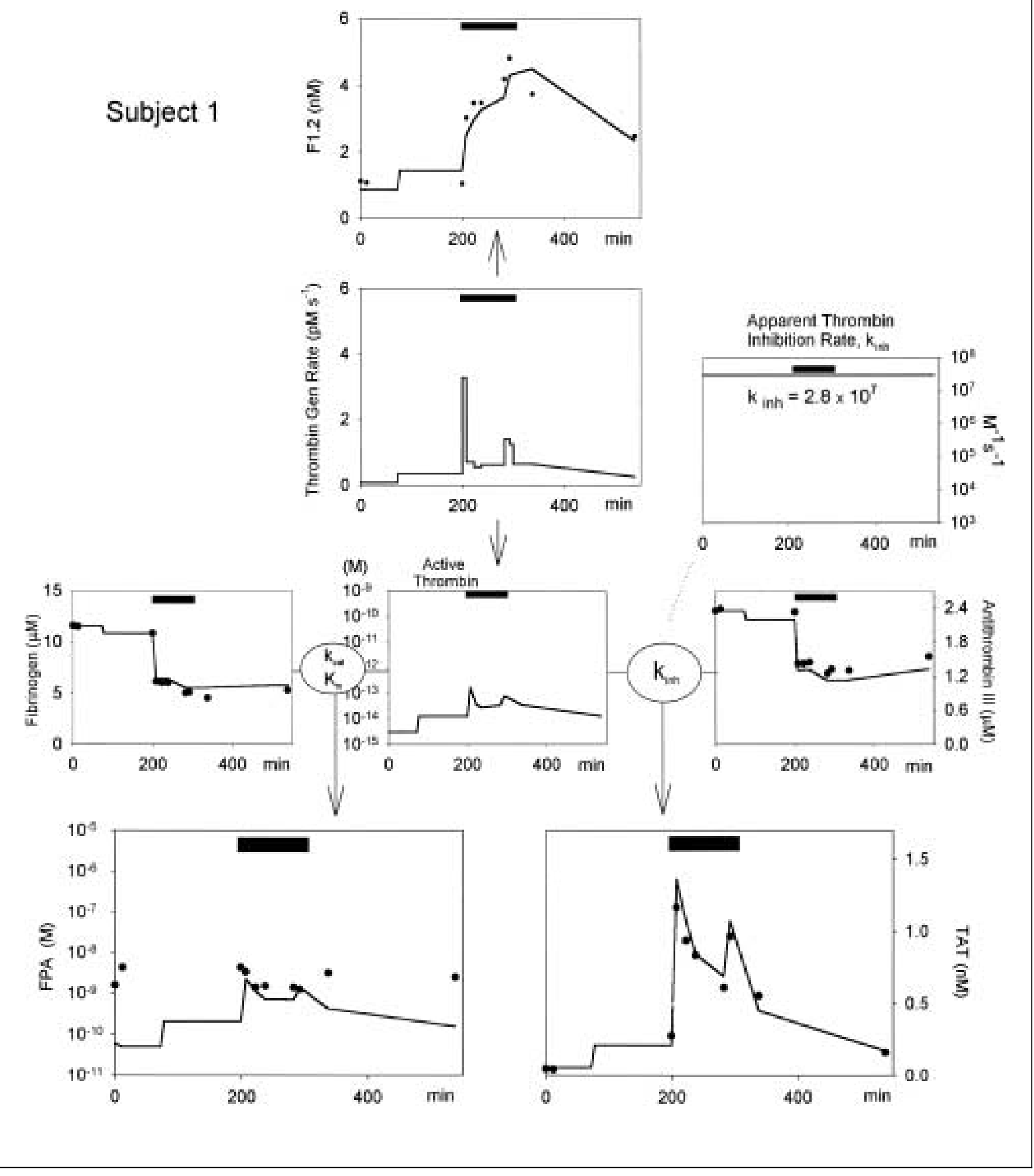


Model $\mathrm{C}$ : fit thrombin inhibition $\mathrm{k}_{\mathrm{inh}}=$ variable

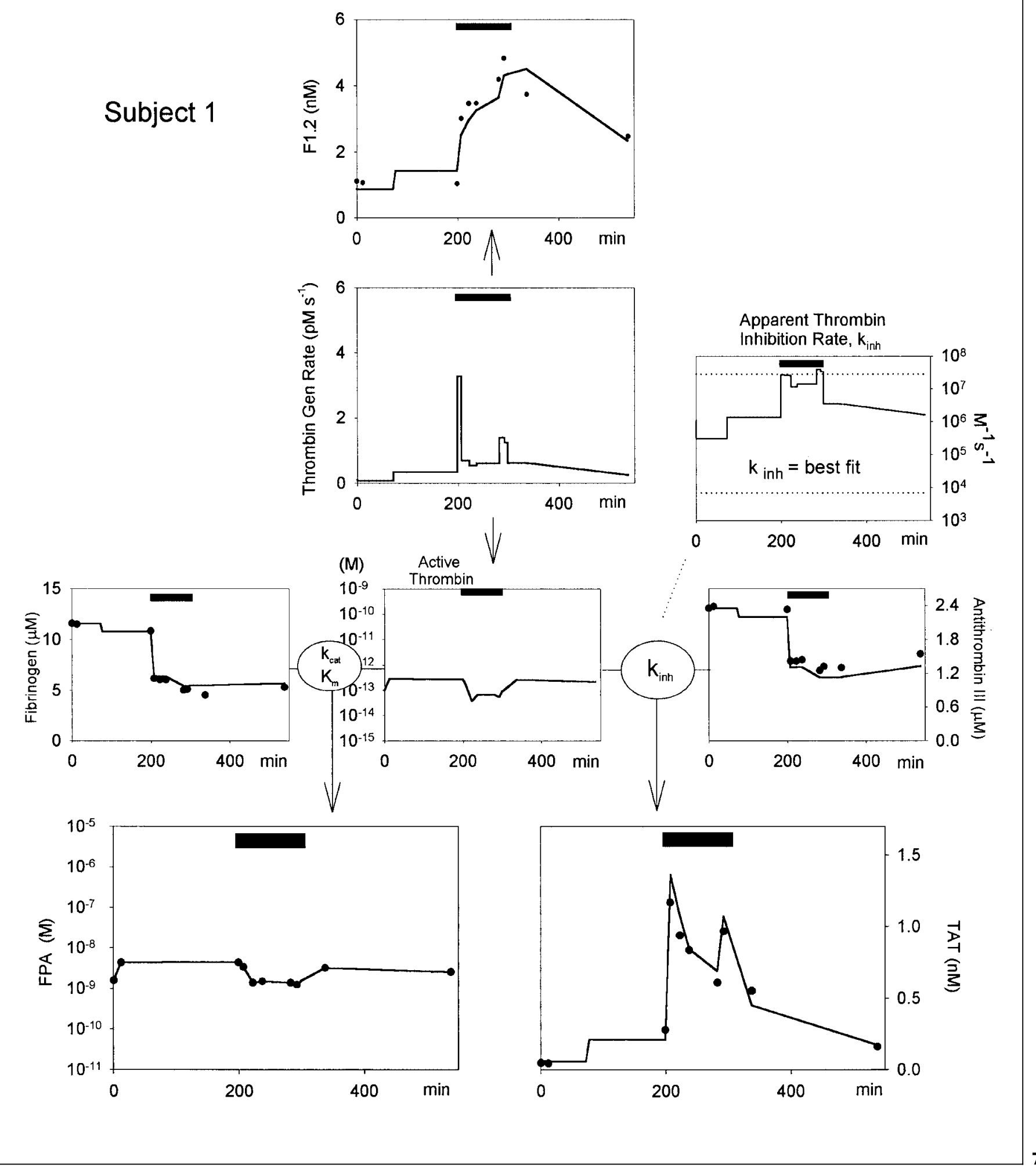




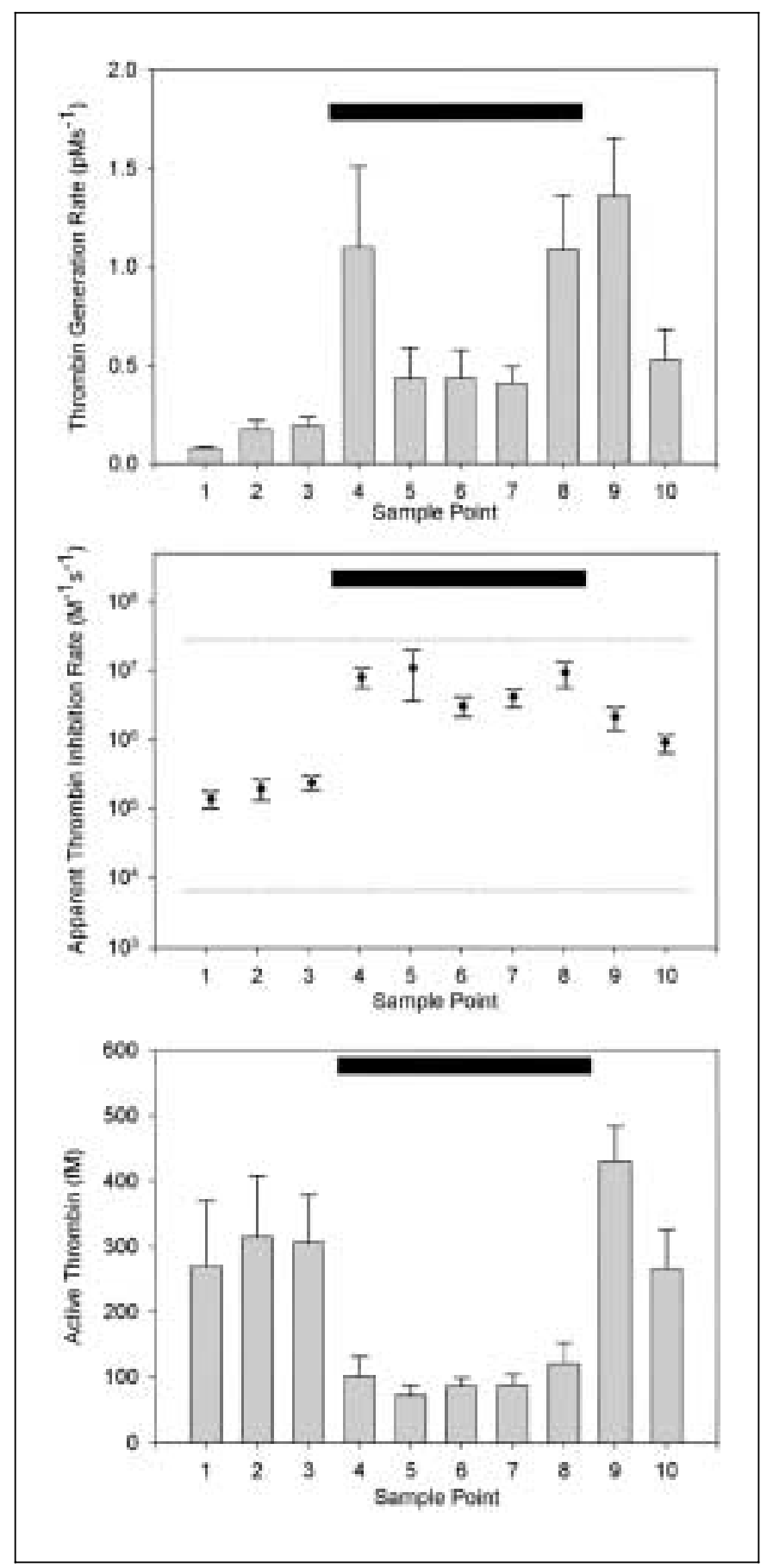

Fig. 8. Average predicted thrombin-generation rate, second-order rate constant for thrombin inhibition by antithrombin and active thrombin concentration during surgery and CPB for all 9 subjects. Data are presented as the mean and standard error. Note that a log scale is used for the y-axis of the thrombin inhibition. Dashed lines in the inhibition rate graph indicate the approximate in vitro rate in the absence of heparin, $0.007 \mu M^{-1} \mathrm{~s}^{-1}$ (lower line), and the approximate in vitro rate in presence of saturating heparin, $28 \mu M^{-1} \mathrm{~s}^{-1}$ (upper line) [11]. The black bar at the top of each graph shows the period of cardiopulmonary bypass.

\section{Discussion}

During normal hemostasis, thrombin is generated at the site of a wound. The majority of the thrombin produced is probably clot bound and relatively resistant to inhibition. Free thrombin in plasma is rapidly inhibited by antithrombin bound to heparan sulfate proteoglycans on the surface of endothelial cells. We estimated that the average $\mathrm{k}_{\text {inh }}$ in vivo under baseline conditions, that is normal hemostasis, is about $0.6 \mu M^{-1} \mathrm{~s}^{-1}$. Faster than the minimum in vitro rate of thrombin inhibition by antithrombin alone $\left(0.007 \mu M^{-1} \mathrm{~s}^{-1}\right)$, but slower than the maximum in vitro rate when antithrombin is saturated with heparin $\left(28 \mu M^{-1} \mathrm{~s}^{-1}\right)$. This average baseline estimate of $k_{\text {inh }}$ suggests that antithrombin is being accelerated to some extent, probably by endothelial heparan. The fact that the baseline rate of thrombin inhibition is not closer to the maximum rate suggests that a substantial fraction of the thrombin is protected from inhibition through binding to fibrin, platelets or other receptors. The model predicted that the average active thrombin concentration during normal hemostasis was about $300 \mathrm{fM}$. The model was not able to estimate how much active thrombin was free versus bound. Early surgery prior to heparinization or starting CPB had little effect on thrombin generation rates, $\mathrm{k}_{\mathrm{inh}}$ or predicted active thrombin concentrations.

Within 5 min after the start of CPB, thrombin generation increased 14-fold while FPA levels and predicted active thrombin levels decreased leading to a predicted 25-fold rise in $\mathrm{k}_{\text {inh }}$ to $15 \mu M^{-1} \mathrm{~s}^{-1}$. Merlini et al. [26, 27] have shown that heparin given for acute coronary syndromes leads to an approximately 50\% reduction in FPA levels, but no change in F1.2 levels, indicating an approximately 2 -fold increase in $\mathrm{k}_{\text {inh }}$ without changing thrombingeneration rates. The large increase in the apparent rate of thrombin inhibition during heparinized CPB compared to heparin therapy alone may be due to a combination of factors including acceleration of antithrombin by highdose heparin given prior to and during CPB and the formation of non-hemostatic thrombin after blood is exposed to the artificial surface of the bypass circuit. It has been suggested that exposure of blood to the large artificial surface of the $\mathrm{CPB}$ circuit constitutes a thrombogenic stimulus that quantitatively as well as qualitatively differs from normal hemostasis [28]. It is possible that nonhemostatic thrombin generated by the artificial surface of the bypass circuit is inhibited faster than clot-bound thrombin formed during normal hemostasis. Thus, CPB results in a paradoxical increase in thrombin generation 
[29-31] but a decrease in active thrombin [29]. The increase in thrombin generation during $\mathrm{CPB}$ has led prior studies to suggest that thrombin activity is also increased during $\mathrm{CPB}$ and that this increase in active thrombin results in activation of other systems including platelets, endothelium, kallikrein/kininogen and other systems [32, 33]. The importance of thrombin formed during CPB in the activation of platelets, endothelial cells and other systems may need to be reexamined.

By $15 \mathrm{~min}$ into $\mathrm{CPB}$, thrombin-generation rates decreased back to towards baseline levels, while FPA and active thrombin concentrations were unchanged, predicting a slightly lower but still elevated $\mathrm{k}_{\text {inh }}$ of $8 \mu M^{-1} \mathrm{~s}^{-1}$. Another burst of thrombin generation occurs when the ischemic heart and lungs are reperfused at the end of $\mathrm{CPB}$. Again while the thrombin-generation rate is increased, the model indicates that $\mathrm{k}_{\text {inh }}$ is also increased to $16 \mu M^{-1} \mathrm{~s}^{-1}$ while active thrombin concentrations remain low. This increase in thrombin generation may be due to ischemic changes to the endothelial cells in the heart that result in transient thrombin generation when reperfusion of the heart occurs. When CPB is complete and after heparin is neutralized by protamine, thrombin-generation rates remain high while the apparent $\mathrm{k}_{\text {inh }}$ decreases to about $5 \mu M^{-1} \mathrm{~s}^{-1}$. Neutralization of heparin decreases the rate of thrombin inhibition, but not back to baseline. By $2 \mathrm{~h}$ postoperatively the thrombin-generation rate, apparent $\mathrm{k}_{\text {inh }}$ and active thrombin concentrations all are slowly returning to normal as the hemostatic system returns to hemostatic thrombin generation.
The precise mechanism of the transient rise in thrombin generation and thrombin inhibition during CPB is not clear, but it suggests that improvements in the biocompatibility of the bypass circuit surface could lead to reduced activation and result in more balanced hemostasis throughout the procedure. Studies using this type of model may be useful in evaluating whether improved bypass circuit materials or other treatments are effective in reducing hemostatic dysregulation during $\mathrm{CPB}$. While the thrombin regulation and circulatory models were used in this study to evaluate patients undergoing $\mathrm{CPB}$, modified versions of these models may be applicable to other situations where thrombin generation and inhibition are rapidly changing and knowledge of the underlying formation rates would be useful. There are several limitations of this study - the assumptions that fibrinogen is the only substrate for thrombin, and that antithrombin is the only inhibitor of thrombin. Also, thrombin is assumed to be a single homogenous pool of solution phase thrombin with only one inhibition rate for each time interval studied, whereas in reality a number of different forms of active thrombin and inhibition rates are present in the vascular system. We had no practical way of evaluating these different pools during CPB and so instead we chose to use an average value. While more complex models are likely to produce slightly different results if other thrombin substrates, inhibitors and thrombin forms were included, they are unlikely to change the principle conclusions of the study since the change in $\mathrm{k}_{\text {inh }}$ was several orders of magnitude.

\section{References}

1 Colman RW, Hirsh J, Marder VJ, Clowes AW, George JN: Natural substrates for thrombin; in Colman RW (ed): Hemostasis and Thrombosis, ed 4. Philadelphia, Lippincott Williams \& Wilkins, 2000, p 178

2 Higgins DL, Lewis SD, Shafer JA: Steady state kinetic parameters for the thrombin catalyzed conversion of human fibrinogen to fibrin. $\mathrm{J}$ Biol Chem 1983;258:9276-9282.

3 Jesty J: The kinetics of inhibition of alphathrombin in human plasma. J Biol Chem 1986; 261:10313-10318.

4 Bock SA: Antithrombin III and heparin cofactor II; in Colman W (ed): Hemostasis and Thrombosis: Basic Principles and Clinical Practice. Philadelphia, Lippincott, 2001, p 321-333.

5 Hoylaerts M, Owen WG, Collen D: Involvement of heparin chain length in the heparincatalyzed inhibition of thrombin by antithrombin III. J Biol Chem 1984;259:5670-5677.
6 Scully MF, Ellis V, Kakkar VV: Comparison of the molecular mass dependency of heparin stimulation of heparin cofactor II:thrombin interaction to antithrombin III:thrombin interaction. Thromb Res 1987;46:491-502.

7 Scully MF, Ellis V, Shah N, Kakkar VV: Effect of heparan sulphate with high affinity for antithrombin III upon inactivation of thrombin and coagulation factor Xa. Biochem J 1989; 262:651-658.

8 Andrew M, Mitchell L, Vegh P, Ofosu F: Thrombin regulation in children differs from adults in the absence and presence of heparin. Thromb Haemost 1994;72:836-842.

9 Chan AKC, Berry LR, Monagle PT, Andrew M: Decreased concentrations of heparinoids are required to inhibit thrombin generation in plasma from newborns and children compared to plasma from adults due to reduced thrombin potential. Thromb Haemost 2002;87:606-613.
10 Downing MR, Bloom JW, Mann KG: Comparison of the inhibition of thrombin by three plasma protease inhibitors. Biochemistry 1978;17: 2649-2653.

11 Jordan RE, Oosta GM: The kinetics of hemostatic enzyme-antithrombin interactions in the presence of low molecular weight heparin. J Biol Chem 1980;255:10081-10090.

12 Weitz JI, Hudoba M, Massel D, Maraganore J, Hirsh J: Clot-bound thrombin is protected from inhibition by heparin-antithrombin III but is susceptible to inactivation by antithrombin III-independent inhibitors. J Clin Invest 1990;86:385-391.

13 Hunt BJ, Parratt RN, Segal HC, Sheikh S, Kallis P, Yacoub M: Activation of coagulation and fibrinolysis during cardiothoracic operations. Ann Thorac Surg 1998;65:712-718.

14 Pelzer H, Schwarz A, Heimburger N: Determination of human thrombin-antithrombin III complex in plasma with an enzyme-linked immunosorbent assay. Thromb Haemost 1988; 59:101-106. 
15 Pelzer H, Schwarz A, Stuber W: Determination of human prothrombin activation fragment $1+$ 2 in plasma with an antibody against a synthetic peptide. Thromb Haemost 1991;65:153159.

16 Amiral J, Walenga JM, Fareed J: Development and performance characteristics of a competitive enzyme immunoassay for fibrinopeptide A. Semin Thromb Hemost 1984;10:228-242.

17 Gram J, Jespersen J: Improved assay of antithrombin-III. Effects of certain additives on thrombin and chromogenic peptide substrates. Clin Chem 1985;31:1683-1688.

18 Clauss A: Gerinnungsphysiologische Schnellmethode zu Bestimmung des Fibrinogens. Acta Haematol 1957;17:237-245.

19 Chandler WL, Velan T: Estimating the rate of thrombin and fibrin generation in vivo during cardiopulmonary bypass. Blood 2003;101: 4355-4362.

20 Bauer KA, Goodman TL, Kass BL, Rosenberg RD: Elevated factor Xa activity in the blood of asymptomatic patients with congenital antithrombin deficiency. J Clin Invest 1985;76: 826-836.

21 Keber D: Mechanism of tissue plasminogen release during venous occlusion. Fibrinolysis 1988;2(suppl 2):96-103

22 Chandler WL, Levy WC, Stratton JR: The circulatory regulation of t-PA and u-PA secretion, clearance and inhibition during exercise and during the infusion of isoproterenol and phenylephrine. Circulation 1995;92:2984-2994.
23 Nossel HL, Yudelman I, Canfield RE, Butler VP, Spanondis K, Wilner GD, Qureshi GD: Measurement of fibrinopeptide $\mathrm{A}$ in human blood. J Clin Invest 1974;54:43-53.

24 Jesty J: The kinetics of inhibition of thrombin by antithrombin in the presence of components of the hemostatic system. Blood 1985;66: 1189-1195.

25 Fischer AP, Benis AM, Jurado RA, Seely E, Teirstein P, Litwak R: Analysis of errors in measurement of cardiac output by simultaneous dye and thermal dilution in cardiothoracic surgical patients. Cardiovasc Res 1978; 12:190-199.

26 Merlini PA, Ardissino D, Bauer KA, Oltrona L, Pezzano A, Bottasso B, Rosenberg RD, Mannucci PM: Persistent thrombin generation during heparin therapy in patients with acute coronary syndromes. Arterioscler Thromb Vasc Biol 1997; 17:1325-1330.

27 Merlini PA, Ardissino D, Rosenberg RD, Colombi E, Agricola P, Oltrona L, Ottani F, Galvani $\mathrm{M}$, Bauer KA, Bottasso $\mathrm{B}$, Bertocchi $\mathrm{F}$, Mannucci PM: In vivo thrombin generation and activity during and after intravenous infusion of heparin or recombinant hirudin in patients with unstable angina pectoris. Arterioscler Thromb Vasc Biol 2000;20:2162-2166.

28 Bagge L, Holmer E, Wahlberg T, Nystrom S-O, Tyden H: Fragmin (LMWH) vs. heparin for anticoagulation during in vitro recycling of human blood in cardiopulmonary bypass circuits: Dose-dependence and mechanisms of clotting. Blood Coagul Fibrinolysis 1994;5:273-280.
29 Gorman RC, Ziats NP, Rao AK, Gikakis N, Sun L, Khan MMH, Stenach N, Sapatnekar S, Chouhan V, Gorman JH, Niewiarowski S, Colman RW, Anderson JM, Edmunds LH: Surface-bound heparin fails to reduce thrombin formation during clinical cardiopulmonary bypass. J Thorac Cardiovasc Surg 1996;111:112.

30 Boisclair MD, Lane DA, Philippou H, Esnouf MP, Sheifh S, Hunt B, Smith KJ: Mechanisms of thrombin generation during surgery and cardiopulmonary bypass. Blood 1993;82:33503357.

31 Valen G, Eriksson E, Risberg B, Vaage J: Fibrinolysis during cardiac surgery. Release of tissue plasminogen activator in arterial and coronary sinus blood. Eur J Cardiothorac Surg 1994;8: 324-330.

32 Ray MJ, Marsh NA, Hawson GAT: Relationship of fibrinolysis and platelet function to bleeding after cardiopulmonary bypass. Blood Coag Fibrinol 1994;5:679-685.

33 Emeis JJ: Mechanisms involved in short-term changes in blood levels of t-PA; in Kluft C (ed): Tissue-Type Plasminogen Activator (t-PA): Physiological and Clinical Aspects. Boca Raton, CRC Press, 1988, vol 2, pp 21-36.

34 Picozzi M, De Cristofaro R: Effect of temperature on the association step in thrombin-fibrinogen interaction. Biochem J 1993;294:563567. 